\title{
Characterization of CYP2C19*17 Polymorphism in a Portuguese Population Sample Relevant for Proton Pump Inhibitor Therapy-A Pilot Study ${ }^{+}$
}

\author{
Adriana M. L. Ferraz ${ }^{1}$, Susana Bandarra ${ }^{1} @$, Paulo Mascarenhas ${ }^{1}$, Isabel Barahona ${ }^{1}{ }^{\circledR}$, Rui Martins ${ }^{2}$ \\ and Ana Clara Ribeiro ${ }^{1, *(\mathbb{D})}$ \\ 1 Laboratoório de Biologia Molecular, Centro de Investigacão Interdisciplinar Egas Moniz (CiiEM), \\ Instituto Universitário Egas Moniz (IUEM), 2829-511 Caparica, Portugal; \\ adrianamlferraz@gmail.com (A.M.L.F.); sbandarra@egasmoniz.edu.pt (S.B.); \\ pmascarenhas@egasmoniz.edu.pt (P.M.); ibarahona@egasmoniz.edu.pt (I.B.) \\ 2 Faculdade de Ciências, Centro de Estatística e Aplicações-Universidade de Lisboa, \\ 1749-016 Lisbon, Portugal; ruimartins@ymail.com \\ * Correspondence: acribeiro@egasmoniz.edu.pt \\ + Presented at the 5th International Congress of CiiEM-Reducing inequalities in Health and Society, Online, \\ 16-18 June 2021.
}

check for updates

Citation: Ferraz, A.M.L.; Bandarra, S.; Mascarenhas, P.; Barahona, I.; Martins, R.; Ribeiro, A.C. Characterization of CYP2C19*17 Polymorphism in a Portuguese Population Sample Relevant for Proton Pump Inhibitor Therapy-A Pilot Study.. Med. Sci. Forum 2021, 5, 19. https://doi.org/10.3390/ msf2021005019

Academic Editors: Helena Barroso and Cidália Castro

Published: 21 July 2021

Publisher's Note: MDPI stays neutral with regard to jurisdictional claims in published maps and institutional affiliations.

Copyright: (c) 2021 by the authors. Licensee MDPI, Basel, Switzerland. This article is an open access article distributed under the terms and conditions of the Creative Commons Attribution (CC BY) license (https:/ / creativecommons.org/licenses/by/ $4.0 /)$.

\begin{abstract}
The interindividual variability of Proton Pump Inhibitor (PPI) therapy results from the phenotype variability associated with the cytochrome P450 2C19 (CYP2C19) gene, namely the CYP2C19*17 allele. Our aim was to characterize patients' genetic variability undergoing PPI therapy. A sample of 33 oral mucosa cells from Portuguese pharmacy patients was collected, followed by genotyping. The allelic frequencies of CYP2C19* 1 (-806C) and CYP2C19*17 (-806T) were $71.2 \%$ and $28.8 \%$, respectively. The genotypic frequencies for CYP2C $19^{*} 1 /{ }^{*} 1$ and CYP2C $19^{*} 1 /{ }^{*} 17$ were $42.4 \%$ and $57.6 \%$, respectively, and 19 of these patients may have a Rapid Metabolizer (RM) phenotype pharmaceutical opinion letter, based on genetic evidence.
\end{abstract}

Keywords: cytochrome P450 2C19; pharmacogenetics; proton pump inhibitors

\section{Introduction}

The genotypic variability associated with the CYP2C19 gene is the pharmacogenetic factor (PGx) that predominantly affects the therapeutic response to PPIs [1]. The CYP2C19*17 polymorphism (-806C $>\mathrm{T})$ results in the replacement of a cytosine (C) with a thymine (T) at -806 nucleotide position in the promoter region of the CYP2C19 gene [2]. The CYP2C19* 17 variant is associated with increased enzyme activity, so the monitoring of patients should be considered in terms of therapeutic failure risk $[1,2]$. The future of PGx in clinical practice may be at the origin of its implementation at community Portuguese pharmacies. In this sense, the present study intends to characterize the genotypic and phenotypic variability of the CYP2C19*17 polymorphism in order to develop a strategy focused and oriented for the Portuguese population.

\section{Materials and Methods}

The analyzed sample corresponds to a total of 33 patients receiving therapy with PPIs at Nobre Guerreiro community pharmacy (Seixal, Portugal); inclusion criteria: over-thecounter PPI therapy prescribed in Portugal; exclusion criteria: $<18$ y.o. without cognitive deficits or language barriers preventing information collection. This study was previously approved by the Ethics Committee of Egas Moniz (EM). DNA extraction was performed according to the manufacturer's instructions from the commercial kit QIAamp ${ }^{\circledR}$. Genotyping was performed using PCR-RFLP. The oligonucleotide primers used for the amplification of CYP2C19*17 were forward $5^{\prime}$-GCCCTTAGCACCAAATTCTC- $3^{\prime}$ and reverse 
5'-ATTTAACCCCCTAAAAAAACACG-3' primers [2]. PCR products were digested with $S f a N I$ restriction endonuclease. For the CYP2C19*17 polymorphism, the wild-type (wt) genotype CYP2C19*1/*1 (-806C/C, 184bp, 139bp and 114bp) and the heterozygous genotype CYP2C19*1/*17 (-806C/T, 218bp, 184bp, 139bp and 114bp) [1,2] were documented. PCR products were purified and sequenced in both DNA directions. The nucleotide sequences were analyzed with BioEdit Alignment Editor V.7.2.5. The statistical analysis was performed using R Statistical software v. 4.0 (Free Software Foundation, Boston, MA, USA) based on the chi-square test $\left(\chi^{2}\right)$ and a $95 \%$ confidence level. Results were compared with those expected for a population in the Hardy-Weinberg (H-W) equilibrium.

\section{Results and Discussion}

In the population studied (21 females and 12 males; 17 Caucasians and 16 Africans, in the age range between 21 and 89 y.o.), the CYP2C19*17 polymorphism is not in H-W equilibrium $(p<0.05)$. There are no significant differences between ethnicities and genders in allelic and genotypic frequencies $(p>0.05)$. Caucasian patients represented a genotypic frequency of $12.1 \%$ for CYP2C19*1/*17 $(-806 \mathrm{C} / \mathrm{T})$ and Negroid patients had a genotype frequency of $36.4 \%$. The female gender had a genotypic frequency of $33.3 \%$ for the genotype CYP2C19* $1 /{ }^{*} 17(-806 \mathrm{C} / \mathrm{T})$ and the male gender represented the genotypic frequency of $24.2 \%$. In the present study, 19 patients have the CYP2C19* $1 /{ }^{*} 17$ genotype $(-806 \mathrm{C} / \mathrm{T})$ associated with the RM phenotype. In these patients, it is necessary to increase the dose to prevent therapeutic failure. The CYP2C19* $1 /{ }^{*} 17$ genotype $(-806 \mathrm{C} / \mathrm{T})$ and the respective RM phenotype were found in the European population (36\%) [1], as well as in the present sample (57.6\%). The CYP2C19*17 allele demonstrated a frequency in Germany (25.5\%), Norway $(22.0 \%)$ and Sweden $(20.0 \%)$ [3] similar to the allelic frequency herein obtained $(28.8 \%)$ (Table 1).

Table 1. Comparison of allelic frequencies of CYP2C19 reported from different populations. Data adapted from 1000 Genomes Project [3] and those obtained in the sample under study.

\begin{tabular}{cccc}
\hline Country & $\mathbf{N}$ & CYP2C19*1 (\%) & CYP2C19*17 (\%) \\
\hline Portugal & 33 & 71.2 & 28.8 \\
Norway & 309 & 62.8 & 22.0 \\
Spain & 346 & 75.0 & 10.0 \\
Germany & 186 & 59.3 & 25.5 \\
Sweden & 185 & 64.0 & 20.0 \\
\hline
\end{tabular}

In conclusion, the implementation of a PGx service is an imperative need for the success of PPI therapy, considering the variability of the CYP2C19 gene and the increasing use of PPIs in recent years, to ensure the success of PPI therapy in Portugal.

Institutional Review Board Statement: The study was conducted according to the guidelines of the Declaration of Helsinki, and approved by the Ethics Committee of Egas Moniz (No. 817 of 29 September 2020).

Informed Consent Statement: Informed consent was obtained from all subjects involved in the study.

Data Availability Statement: The data presented in this study are available on request from the corresponding author.

Acknowledgments: Nobre Guerreiro community pharmacy (Amora, Portugal) and the Health Centre of Amora. This work was part of Adriana Ferraz's master degree in Pharmaceutical Sciences and it was supported by EM.

Conflicts of Interest: The authors declare no conflict of interest. 


\section{References}

1. Lima, J.J.; Thomas, C.D.; Barbarino, J.; Desta, Z.; Van Driest, S.L.; El Rouby, N.; Johnson, J.A.; Cavallari, L.H.; Shakhnovich, V.; Thacker, D.L.; et al. Clinical pharmacogenetics implementation consortium (CPIC) guideline for CYP2C19 and proton pump inhibitor dosing. Clin. Pharmacol. Ther. 2020, 109, 1417-1423. [CrossRef] [PubMed]

2. Dehbozorgi, M.; Kamalidehghan, B.; Hosseini, I.; Dehghanfard, Z.; Sangtarash, M.H.; Firoozi, M.; Ahmadipour, F.; Meng, G.Y.; Houshmand, M. Prevalence of the CYP2C19*2 (681 G>A), *3 (636 G>A) and *17 (-806 C>T) alleles among an Iranian population of different ethnicities. Mol. Med. Rep. 2018, 17, 4195-4202. [CrossRef] [PubMed]

3. International Genome Sample Resource. 1000 Genomes Project. Available online: https://www.internationalgenome.org (accessed on 10 December 2020). 